\title{
Cyberspace Narratives for Global Interconnectivity Based on Content Analysis of Financial Media in Comparison
}

\author{
Jingwei Piao , Yancong $\mathrm{Su}^{2, *}$ \\ ${ }^{1}$ School of Film, TV, and Communication, Xiamen University of Technology, No.600 Ligong Road, Jimei District, Xiamen, 361000. \\ China \\ ${ }^{2}$ School of Design Art, Xiamen University of Technology, No.600, Ligong Road, Xiamen, 361024, Fujian, China
}

\begin{abstract}
The paper explores the role of elite financial media in construction narratives of global interconnectivity, in a comparative framework[7]. The existing era of globalization provided us with new challenges for strategic intelligence as the virtual compression of time along with new technological achievements in shorter period of time and potentially cataclysmic threats[8]. Two globally circulated financial journals - Caijing, China's leading financial news organization, and the Economist, with a vital influence across the globe - are chosen to manifest the diverse media discourses representing, respectively, the Chinese and Anglo-American socio- economic backgrounds. The paper aims to use the quantitative content analysis to answer the question: what are the narrative characteristics of the Caijing and the Economist in portraying China's economic globalisation? The study are designed to tackle a specific focus on the globalised elite communication, in order to guide the investigation of China's global interconnectivity in a hybridizing and contesting way[4]. Like other forms of mediated electronic connectivity, the Internet instead of circumscribing sovereignty has offered centralised authority new ways of conducting statecraft, by circulating ideas that represents the consensus shared by global elites.
\end{abstract}

\section{Introduction}

The paper treats financial media as a particular genre, from a perspective of how it narrating the topics of China's economic globalisation [1]. It examines the online published discourse, in which the contesting idea of laizzez faire primarily referring to the conflict between the state and the market[2]. Both as economic idea and practice, free market concept closely linked not only to the campaigns of economic liberalisation in the late 1980 s, but also, to the transformation of markets in emerging economies.

Therefore, the paper discusses the narrative characteristics, particularly the style of reporting, of two outstanding elite financial with their influential online archives - the British journal, The Economist, which maintains a worldwide readership, and Caijing, China's leading financial magazine - in narrating China's global economic integration.

With the regard to investigate the topic in the narratives of markets, three key events are considered as representative in understanding such media discourse: China's accession to the World Trade Organisation (WTO), Foreign listing (IPO), and Outward Direct Investment $(\boldsymbol{O D I})$.

The paper employs a ten-year time span from 1998 to 2008, based on the consideration that it includes major economic events and controversial discussions of China's integration, and it justifies the existence of Caijing as its chief editor $\mathrm{Hu}$ Shuli who is also the opinion leader resigned in 2009.

\section{Define the Style of article}

The style mirrors particular means of narrating so that language elements are scheduled and sequenced in certain ways to reflect editorial decision and target at a particular group of audience. Style is considered to be more precise to count how diversely two journals distribute three news events from a big picture that represents the editorial orientation. The coding scheme are made through defining the characteristics of different types of style[3]. In a conventional way, a Style of news article can be defined by its structural elements, which includes headline, subhead, and a lead or intro; or formulated structure, for instance an inverted pyramid formula; or other editorial stances, such as news value of timeliness, proximity, and prominence. But these judgments need to be adapted to the style of two selected elite magazines, as they have developed distinguished style of reporting for elite readers and in reporting professions of economics and finance.

- News-refer to the events with not too much comment or opinion. The news items are often shorter and mostly within one page. 
- Editorial - appears to be in a fixed format that features a distinctive opinionated style.

- Feature-cover stories with more investigated information and opinion.

- Special Report-is a separated section in both magazines. They are explicitly tagged for a particular subject that umbrella several smaller topics in much extended context.

- By Invitation - is the piece of article written by decision makers from markets and states.

- Exclusive Interview - is defined as the kind that contain mostly the interviews with top professionals from business and politics

\section{Findings and discussions}

Table1 presents the prominence of every Style category in narrating the selected topics for two journals in

Table 1. Prominence and frequency of Styles absolute amount and relative percentage to total number of articles. The calculation stated below shows the relative attention paid to style of articles in each media:

$$
\% N_{(\text {topic })}^{(\text {style })}=\frac{N_{(\text {topic })}^{(\text {style })}}{\text { Total } N_{(\text {topic })}} \times 100 \%
$$

The ratios echo the frequency or relative attention to each style of article in comparing two media rather than in absolute amounts (Figure 1). The two journals prefer the style of Feature across prominently all three events, especially in reporting the overseas IPO and investments. Because the topic of WTO accession contains two many subjects, the style shows much more diversity, with News, Features, and Editorials relatively more evenly distributed, in contrast to those of the other two events.

\begin{tabular}{|c|c|c|c|c|c|c|}
\hline & \multicolumn{3}{|c|}{ The Economist } & \multicolumn{3}{|c|}{ Caijing } \\
\hline & WTO & IPO & ODI & WTO & IPO & ODI \\
\hline \multirow{2}{*}{ News } & 72 & 2 & 4 & 82 & 25 & 12 \\
\hline & $43.9 \%$ & $6.9 \%$ & $7.8 \%$ & $28.5 \%$ & $15.8 \%$ & $19.7 \%$ \\
\hline \multirow{2}{*}{ Editorial } & 21 & 0 & 4 & 31 & 18 & 2 \\
\hline & $12.8 \%$ & & $7.8 \%$ & $10.8 \%$ & $11.4 \%$ & $3.3 \%$ \\
\hline \multirow{2}{*}{ Feature } & 50 & 18 & 33 & 70 & 82 & 42 \\
\hline & $30.5 \%$ & $62.1 \%$ & $64.7 \%$ & $24.3 \%$ & $51.9 \%$ & $68.9 \%$ \\
\hline Special & 18 & 9 & 10 & 10 & 6 & 0 \\
\hline Report & $11 \%$ & $31 \%$ & $19.6 \%$ & $3.5 \%$ & $3.8 \%$ & \\
\hline By Invitation & $\begin{array}{c}3 \\
1.8 \%\end{array}$ & 0 & 0 & $\begin{array}{c}67 \\
23.3 \%\end{array}$ & $\begin{array}{c}19 \\
12 \%\end{array}$ & $\begin{array}{c}4 \\
6.6 \%\end{array}$ \\
\hline $\begin{array}{c}\text { Excl. } \\
\text { Interview }\end{array}$ & 0 & 0 & 0 & $\begin{array}{c}28 \\
9.7 \%\end{array}$ & $\begin{array}{c}8 \\
5.1 \%\end{array}$ & $\begin{array}{c}1 \\
1.6 \%\end{array}$ \\
\hline
\end{tabular}




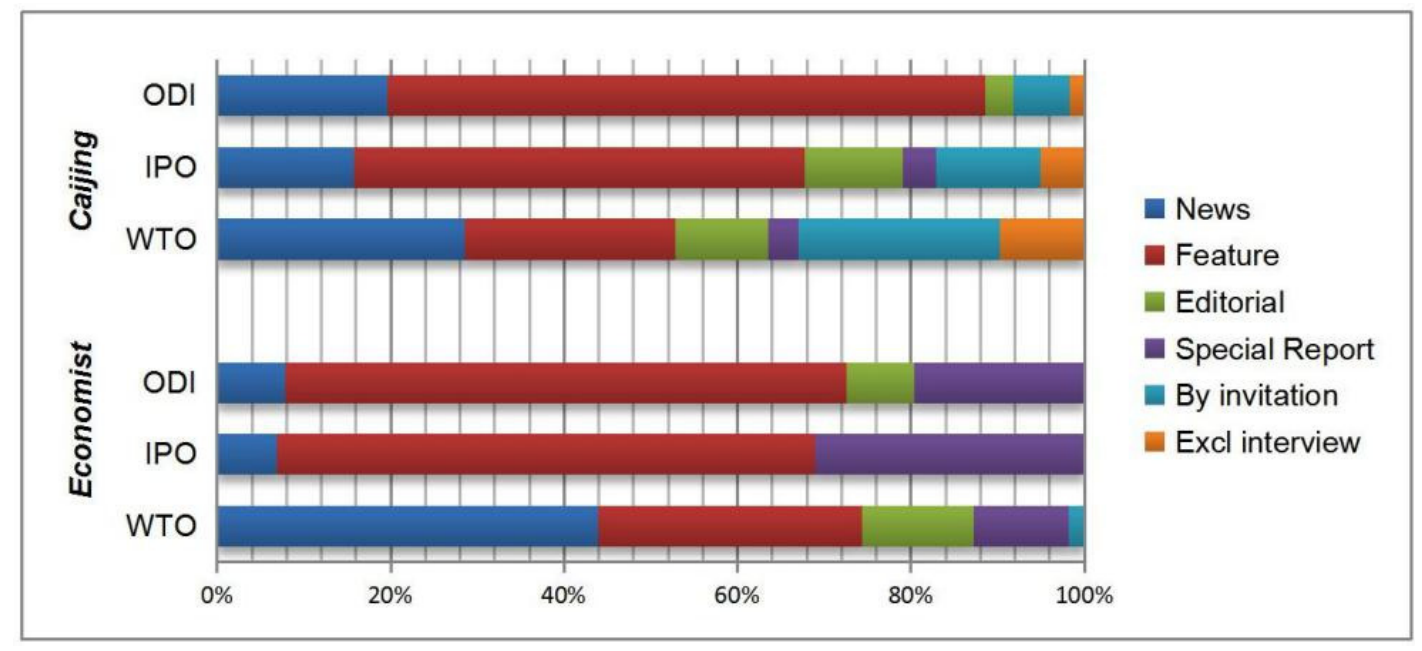

Figure 1. Relative frequency of style

However, articles that are more opinion biased appears to be devoted to WTO accession reporting in two journals, except that Caijing prefers to adopt the Editorials on overseas listing, because the younger magazine play a similar role as the early version of the Economist to educate domestic market with financial knowledge. The relative percentage to total number of each style presents the resemble preference of narrating style. By comparing with the absolute numbers, Feature articles appear to be favoured in covering the stories of overseas IPO IPO ( $\% N_{\text {IPO }}^{\text {Feature }}$ shows $62.1 \%$ and $51.9 \%$ respectively) and outward direct investments $\left(\% N_{\text {ODI }}^{\text {Feature }}\right.$ shows $64.7 \%$ and $68.9 \%$ respectively) than WTO accession $(30.5 \%$ and $24.3 \%)$, which contains mostly fact-based news for two journals. In a holistic picture, the more insightful articles with deep investigations and analysis that are categorised by Editorials, Special Report, By invitation, and Exclusive Interviews, are more evenly distributed in the British journal at about $30 \%$. However, the proportion is obvious skewed toward WTO entrance in the Chinese journal, accounting for $50 \%$.

One of the distinct difference between two magazines is that Caijing is more likely to employ excessively the external narrators than its British counterpart. As Table 1 shows, particularly for the stories of WTO entrance, $N_{W T O}^{B y \operatorname{Inv}}$

equals to 67 in Caijing and only 3 in The

Economist; $N_{W T O}^{\text {Excl Int }}$ is 28 in Caijing and none for its counterpart. Because The Economist prefer to form the narratives with their own editorial judgments by extending the contexts to the extent how other parties and events could be influenced in different perspectives (as the WTO of Caijing is 10 compared with 18 in The Economist). Generally speaking, the Economist conceals much less authoritative narrators than its Chinese counterpart, as total $\mathrm{N}^{\text {ByInv }}$ and $\mathrm{N}^{\text {ExclInt }}$ equaling to barely 3 in The Economist, contrasting to 127 in Caijing. The Economist favours the Special Report written by its own staff, who have no bylines on the pages. Comparing with other types, Special Report intents to investigate and do analytical works more insightfully from international perception. In Figure I, the distribution of style echoes such comparison. An apparent answer to this contrast is that Caijing maintains much better contacts with Chinese elites who are reporting targets and participants in the reporting events.

Cross comparing three events, two journals manifest different characteristics of adopting narrative style. For the stories of overseas IPO, different narrative styles are more evenly distributed in the Chinese journal. However, the British journal emphasis on three main types of styles. The absolute numbers shows that the Economist doesn't pay too much attention to the overseas listing events, but scattered information are also mentioned in other pieces. Caijing serves one of its primary function of educating domestic financial market, so that it covers the topic in a comprehensive manner with all narrating style. On contrast, the Economist prominently covers overseas direct investment, because most of the cases indicated prolonged impact on global marketplaces, and even ideological significance with reference to the corporate cultures and national politics.

\section{Conclusion}

Across comparing three stories of narration, the WTO entrance is mostly reported with various styles for both two journals, with News, Features, and Editorials much more evenly distributed. To wrap up, two financial magazines prefer the style of Feature apparently for all three events. The similar narrative characteristic primarily manifests the strategies of media agenda setting by two journals. The conclusion tentatively indicates that the holistic quantitative similarities represent a general picture of how elite financial media narrate the topic in a shared professional manner [5]. The Economist and Caijing both have developed the influence among small circle of elite, as they manage to mingle the professionalism of financial journalism with business practice, abstract economic theories, and political stances [6]. The language of shaping the imaged economic reality carries the function of the literary forms 
that inform, educate and entertain particular social group [7]. Like other forms of mediated electronic connectivity, instead of restraining sovereignty has provided hegemonic authority fresh ways of conducting statecraft, by articulating ideas that represents the consensus shared by global elites.

\section{Acknowledgments}

This work was supported by XMUT Studies of Social Science under grant No. YSK17007R, and the Young Teachers Fund of the Provisional Educational Department of Fujian under grant No. JAS 180390.

\section{References}

1. Andrew J 1995 How to understand financial press (London: KoganPress).

2. Bal M 1990 The point of narratology Peotics Today 11(4) pp 727-53.

3. Borden M J 2007 The role of financial journalists in the corporate governance Fordham Journal of Corporate and Financial Law XII pp 312-70.

4. Davis A 2006 Media effects and the question of the rational audience: lesions from the financial market Media, Culture \& Society 28(4) pp 603-625.

5. Parsons W 1989 The power of financial press: journalism and economic opinion in Britain and America Aldershot: Edward Elgar

6. White H 1996 The value of narrativity in the representation of reality Critical Inquiry 7(1) pp 527.

7. John P B 2019 A Declaration of the Independence of Cyberspace' Electronic Frontier Foundation (available at: https://www.eff.org/cyberspaceindependence accessed).

8. Manwaring S 2020 Always in control Sovereign states in cyberspace (Cambridge University Press) 5(4). 